\title{
The use of medications by elderly men with polypharmacy: representations and practices
}

\author{
Guilherme Oliveira de Arruda' \\ Silvia Cristina da Silva Lima² \\ Rogério Dias Renovato ${ }^{3}$
}

\begin{abstract}
Objectives: this study aimed to investigate and understand the use of medications by elderly men, their representations and the subsequent practices. Methods: this is a qualitative, descriptive and exploratory study, in which there participated 17 elderly men, with polypharmacy, and assisted under the Family Health Strategy in the Municipality of Dourados in the Brazilian state of Mato Grosso do Sul (MS). Results: the results show that most of the medications are used for treating cardiovascular disorders. The elderly men develop strategies considering the prescription of these, adapting in line with their own perceptions and meanings. From these tactics emerge representations on youth and old age, in which old age is associated with illness. In addition, practices were observed which sought to associate the use of medications with medicinal plants, re-signifying the process of being ill. Different perspectives of masculinity permeate the use of medications, sometimes reinforcing hegemonic conceptions, and sometimes revealing alternate models of masculinity. The woman is present in the care with the use of the medications. Conclusions: in this context, the health team, above all that of nursing, must assist the elderly man in his practices of medication, taking into account his representations, his protagonism, and the role of the woman as a support in the care.
\end{abstract}

Descriptors: Drug Utilization; Primary Health Care; Men's Health; Health of the Elderly.

\footnotetext{
${ }^{1}$ Master's student, Departamento de Enfermagem, Universidade Estadual de Maringá, Maringá, PR, Brazil

${ }^{2} \mathrm{RN}$, Specialist in Urgency and Emergency Nursing.

${ }^{3}$ PhD, Adjunct Professor, Universidade Estadual de Mato Grosso do Sul, Dourados, MS, Brazil.
}

Corresponding Author:

Guilherme Oliveira de Arruda

Rua Carlos Weiss, 39, Apto. 702

Zona 7

CEP: 87020-310, Maringá, PR, Brasil

E-mail: enfgoa@gmail.com
Copyright (๑) 2013 Revista Latino-Americana de Enfermagem This is an Open Access article distributed under the terms of the Creative Commons Attribution Non-Commercial License (CC BY-NC).

This license lets others distribute, remix, tweak, and build upon your work non-commercially, and although their new works must also acknowledge you and be non-commercial, they don't have to license their derivative works on the same terms. 


\section{Introduction}

Studies on men's health increased in the last decade of the XXth century, but gaps still remain, such as greater specificity, and the development of research seeking to understand men's experiences vis-à-vis their health, on how they manage their treatment in the experiences of becoming ill, and, finally, how they access the health services ${ }^{(1)}$. The naturalizations of social constructions on masculinity create difficulty in the perception of the health needs of the men seeking the health services. One study undertaken with primary health care professionals in four Brazilian states shows that the men's illness seems not to find care spaces, favoring its invisibility, and that the embracement in the health services seems to be rather problematic(2).

In research undertaken in Australia with 36 elderly men, ambivalence was ascertained in the discourses regarding health ${ }^{(3)}$. Sometimes it is intermingled with reluctance to seek the help of the health services, and surrounded by behaviors which reaffirm independence and autonomy, but which intersect with possibilities from other identity matrixes, such as awareness of their vulnerabilities, the concern with illness, and the search for care, as was ascertained in an investigation in Scotland, involving 12 elderly men ${ }^{(4)}$. It is understood that these conceptions can be broadened to the use of medications and are interwoven with historicallyconstructed representations.

As yet there has been little qualitative research on the use of medications in elderly men, and what there is usually focusses on specific groups of drugs, such as the anti-depressants( $^{(5)}$ and the anti-inflammatories ${ }^{(6)}$. In an American study involving 68 elderly men, the reluctance these reported to use anti-depressants is anchored in negative representations of these medications, such as the fear of experiencing adverse reactions or of becoming dependent(5). In separate research, on the other hand, involving elderly men in Australia, it was ascertained that there was insufficient comprehension of the risks related to anti-inflammatories, and some accounts evidenced perceptions of absence of adverse reactions and toxicity(6).

In relation to qualitative approaches to the use of medications by elderly men, studies are few, as verified by a metasynthesis on 37 qualitative studies, none of which addressed this population(7), even taking into account that in this stage of life, the prevalence of polypharmacy is high, as observed in a study with 800 elderly people in the city of Rio de Janeiro, Brazil, where approximately half of the sample made use of between one and four medications, and a third were taking five or more ${ }^{(8)}$.

The few qualitative studies on the use of medications among elderly men have prioritized the issues of erectile dysfunction, baldness, the andropause ${ }^{(9)}$, osteoporosis(10) $^{(10)}$ the use of medicinal plants(11). As a result it is necessary to increase the number of investigations, given that the use of medications meets other components, such as male sexuality, ageing, esthetics, appearance and other alternative therapies. In this regard, the present research's objective was to investigate and understand the use of medications by elderly men with polypharmacy, their representations, and the subsequent practices.

\section{Methodology}

This is a study with a qualitative, descriptive and exploratory approach, whose theoretical inputs have, as their framework, Peter Conrad's conceptions of practices of medication ${ }^{(12)}$ and the concept of representations proposed by Stuart Hall(13). The sample, made up of 17 elderly men, registered in four Family Health Strategy (FHS) centers in Dourados, Mato Grosso do Sul, was defined by convenience, obeying the principle of saturation.

The following were adopted as inclusion criteria: to be 60 years old or over, to be assisted by the FHS in the Municipality of Dourados, to make use of four medications or more, which characterizes polypharmacy ${ }^{(14)}$, and to consent to participate in the study. The persons eligible to participate in the study were recruited through previous contact with Community Health Workers. Fifteen subjects, however, could not participate, for a variety of motives: they were not at home, there were errors of address, or they were unable to respond on their own (reduced auditory acuity and difficulty in speaking caused by cerebrovascular disease).

The interviews were held between May and September 2010, narrative interview being used, as a form of obtaining access to the meanings attributed to the individuals' experience and to the interpretations regarding the reality of everyday life. Focus was on the

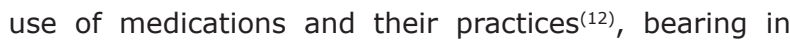
mind the temporal perspective, from times passed to times present.

The narrative interview contains the following stages: preparation, initiation, main narration, the questions, and the conclusive account ${ }^{(15)}$. The guiding 
questions for the interview were: Tell me about your previous experiences in relation to the use of medications, referring to your childhood, youth, and adulthood and Tell me about your current experiences in relation to the use of medications in your day-to-day. So as to describe the interviewees' characteristics, their medical records were checked regarding the following information: age, marital status, education, previous occupation, and place of origin. The data on the medications was supplemented based on the medical prescriptions which the elderly men had in their homes.

The analytical route occurred through detailed readings of the narrative material which made possible immersion in the discourses and the verification of the statements as happenings which took place in the subjects' space and time. So as to organize the narratives in units of analysis, the authors used the Foucaultian perspective, which proposes to refuse single explanations and, equally, the insistent search for the ultimate meaning or the hidden meaning of the things, considering the basic elements of the discourse: the reference to something we identify; a subject which can effectively affirm that; the fact that it does not exist in isolation, but always in association with other discourses; and the materiality of the discourse ${ }^{(16)}$.

The theoretical inputs of the analysis stage were the concept of Conrad's practices of medication ${ }^{(12)}$ and of representations, based on Stuart Hall(13). In relation to the practices of medication, the analytical route took into account the elderly men's non-linear actions regarding the instructions in the doctors' prescriptions, in this way making it possible to explore the types of tactic and strategy elaborated by the subjects, that is, to perceive in these human beings their protagonism considering the medical prescriptions ${ }^{(12)}$. The practices of medication become closer to the ways of doing in the everyday, in which society seems to establish coping mechanisms, ways of doing through which the users take back the space organized by the techniques of socio-cultural production(17).

Regarding the concept of representations, language emerges as a producer of meanings which regulate effects and social practices. In the search to investigate and understand the representations, the analysis of the narratives through reading and interpretation reveals the concreteness of the meanings linked to the use of medications by elderly men, seeking to perceive how they are constituted as life experiences which are significant to them. The representations are constructed and produced, and are negotiated and shared, and may acquire other meanings in new situations ${ }^{(13)}$.

The interviews were recorded and transcribed in full and the accounts were edited, so as to eliminate language habits, while keeping the meaning of the statements. Each elderly man received a code, H.1, H.2, $\mathrm{H} .3$, so as to ensure their anonymity. The present study followed the recommendations of Resolution $n^{\circ} 196 / 96$ of the National Health Council, and met the ethical and fundamental requirements for research with human beings. The project was approved by the Research Ethics Committee of the Federal University of Mato Grosso do Sul, under protocol $n^{\circ} 1623$, issued $4^{\text {th }}$ March 2010.

\section{Results and Discussion}

\section{Characterization of the Interviewees}

The elderly men interviewed had a mean age of 68 years, in the age range between 60 and 81 years old. Most were retired, from other states, and lived with their wives; some still maintained some form of activity which supplemented their family income: among these elderly men's professions, twelve mentioned being autonomous and five worked for companies, performing different roles. (Figure 1 ).

\begin{tabular}{|c|c|c|c|c|}
\hline Interviewees & Age (years) & Marital status & Education & $\begin{array}{c}\text { Brazilian state } \\
\text { of origin }\end{array}$ \\
\hline H.1 & 62 & Married & Higher & Paraná (PR) \\
\hline H.2 & 81 & Married & Junior High & Tradesman \\
\hline H.3 & 70 & Married & Illiterate & Carpenter \\
\hline H.4 & 71 & Married & Junior High - not finished & Industrial machine operator \\
\hline H.5 & 61 & Married & Junior High & Painter \\
\hline H.6 & 80 & Married & Junior High not finished & Dry-cleaner \\
\hline H.7 & 60 & Single & Junior High not finished & Driver \\
\hline H.8 & 60 & Married & Junior High not finished & Driver \\
\hline H.9 & 61 & Married & Senior High & São Paulo (SP) \\
\hline H.10 & 77 & Married & SP & Tradesman \\
\hline
\end{tabular}

(The Figure 1 continue in the next page...) 


\begin{tabular}{|c|c|c|c|c|c|}
\hline Interviewees & Age (years) & Marital status & Education & Previous occupation & $\begin{array}{c}\text { Brazilian state } \\
\text { of origin }\end{array}$ \\
\hline H.11 & 67 & Single & Junior High & Builder & MS \\
\hline H.12 & 82 & Widower & Junior High not finished & Farmworker & Sergipe (SE) \\
\hline H.13 & 68 & Married & Junior High not finished & Supervisor & PE \\
\hline H.14 & 66 & Married & Illiterate & Carpenter & Bahía (BA) \\
\hline H.15 & 71 & Single & Junior High not finished & Tradesman & PE \\
\hline H.16 & 65 & Married & Junior High not finished & PR \\
\hline H.17 & 60 & Single & Junior High not finished & Cattle raiser & MS \\
\hline
\end{tabular}

Figure 1 - The elderly men's socio-demographic characteristics. Dourados, MS, Brazil, 2010

The main disorders found were of the cardiovascular system, including metabolic and mental disorders. In relation to the medications used, a predominance of medications related to cardiovascular disorders was ascertained, including captopril, hydrochlorothiazide, enalapril, losartan, digoxin, simvastatin, carvedilol, atenolol and chlorthalidone. This finding contributes to the prominent position of the cardiovascular illnesses in the profile of morbi-mortality among the elderly men, and in the wide prescribing of these medications ${ }^{(18)}$.

\section{The use of medications as routine practices, and ambivalences perceived}

In relation to the use of the medication, these seem to be inserted into the elderly men's routine, integrated into their daily tasks, as one can see in H.1's discourse: [...] Simvastatin is once a day. The atenolol is twice a day, and the captopril is twice a day. So I take three early, and three at night. This one here is only at night. This one here, is only in the morning. This one is once at night, and this one, once in the morning. The incorporation of these therapeutic artifacts sounds familiar, being one of the components of their day-to-day actions. It is, however, necessary to problematize the incorporation of the medications in the elderly men's routine, avoiding the naturalization of this phenomenon which is linked to the experiences of illness and to the elderly man's insertion into the health systems.

According to H.8's account:[...] I didn't feel anything, I had high blood pressure, it turned out I had heart problems, in both legs. That's why I take simvastatin and aspirin. As can be seen in the examples, the incorporation of the use of medications into the life of the elderly man follows the model of Western medical rationality. This mode of understanding health needs conceives of the body as a 'machine', which can uniquely prioritize injuries to it to the detriment of the subjective and interactive dimensions which involve the individual in his practices and conceptions; in its medicalization and actions it has the tendency to overshadow the illness's social dimension, hindering attention to the real statements of male un-met needs by the health service ${ }^{(19)}$.

Sometimes, the incorporation of the use faces manifestations of non-acceptance which permeate the interviewees' accounts: [...] but I take them because I have to, because you have to take them, but I don't miss anything (H.1); [...] I didn't want to take them, but I can't stop, so I have to take them, because I don't want to. But I am obliged to take them (H.10). Such manifestations may be linked to the fact that the treatment requires discipline and commitment for a long period of their lives, being configured as an obligation.

It is possible that the non-acceptance can increase the chances of non-adherence to the drug therapy, as well as the discontinuation of the use of the medications. The possibility of establishing the normality of the body, offered by the medication, facilitates the elderly man's appropriate following of the therapy. In contrast, negative experiences previously lived through, and the obligatory character of the use of the medication, can create an aversion to undertaking this practice, leading to other tactics by the elderly man ${ }^{(20)}$.

In using various medications, as $\mathrm{H} 2$ notes: [...] there were about four kilos of medications, for me to take all at once $[\ldots]$, many elderly men report negative experiences in relation to the drugs, such as adverse reactions, which contrast with the medications' potential efficacy and curative capacity ${ }^{(11)}$. The gaze switches from the medication to the human being, as the language used by the elderly man in relation to the medications' quantity/dosage is positioned as a central subject of this encounter, and reveals meanings linked to the polypharmacy. Feelings on taking multiple medications seem to contrast the naturalization of this practice, being permeated with representations which involve disputes and tensions between what health and illness are. 
The elderly men and their protagonism considering the use of medications

In the elderly men's discourses, one can perceive modes of doing in the routine which permit the reappropriation of the space and organization of resistance which is established in the face of the prescriptions for medications, that is, some practices of medication: [...] I stopped and spent more than one month without taking them (H.10); [...] depending on where I am and whether I feel it to be necessary, I immediately take the medicine (H.4). These practices, considered irrational, are strategies used by the elderly men, and may be understood based on Conrad's explicatory model(12). For this author, the users of the medications exercise protagonism, being able to comply with the instructions specified in the prescriptions, as well as to establish forms of maintaining their own role, and thus to modify them in line with their needs, desires or own conceptions.

In the account of H.4, one can observe these protagonistic tactics: [...] the weather changes and the nerve hurts, like it's hurting now; because of the humidity, so it starts hurting and burns; I have to take the medicine for pain, in that case I take it... it depends, I take various medicines for pain, depending on the pain and what I am feeling, I take diclofenac or dipyrone. It is considered that the elderly man can exercise his complicity in the hegemonic model of masculinity, that is, the model of the man who is strong, independent and invulnerable, and exalting his active form over the care ${ }^{(19)}$, including over the use of medications.

It may be perceived that for this elderly man, the climatic changes, humidity and type of pain are configured as significant elements in the choice of the medication. Viewed through the prism of the representations as a creative process, it is revealed how the individual represents the materialization of the thinking, that is, how the notions of therapeutic practices guide his actions. In this way, knowledges, experiences and representations influence the use of medications, it being the case that the health professionals may not take this into account in the care process ${ }^{(21)}$.

In the case of H.1: If I forget one day, the next day I go back to the normal time. To go three or four days without taking it, I don't do that $[\ldots]$, he does not go for a long period without the medication, but admits to failures, and to the corrections which he judges to be appropriate. It should be noted that these elderly men make use of the medications based on the medical prescriptions, which they themselves presented during the interviews, although they use these artifacts in line with their perceptions and meanings.

These findings were also verified in research involving older adults with osteoarthritis. The perceptions of reliability and efficacy were shown to be diverse in relation to the anti-inflammatories, paracetamol, glucosamine and chondroitin used. The representations of the superiority of the anti-inflammatories in relation to the others led to differentiated practices of medication, which led this group of subjects to have less difficulty in using them in their daily routine, even experiencing adverse reactions ${ }^{(22)}$.

Thus, among the elderly men, such practices should be monitored, so as to identify tactics which may pose risks to health, and need evaluation from a qualified professional. Sensitization regarding healthy practices must be strengthened by primary health care professionals, due to their privileged contact with the community, including with the elderly men in the area they cover.

\section{The use of medications and the interface between youth and ageing}

In this relationship, it is possible to investigate the association that the elderly man makes between the process of ageing, illness and the use of medications as a way of normalizing the body, which shows the representations regarding the incorporation of the medications in the daily routine and the corresponding practices of medication. It is possible to understand this relationship based on the following accounts: [...] I started getting worse six years ago, seven years more or less (H.2). [...] until I was twenty, when I got married, I didn't have health problems, I had no problems with colds, no problems with cold, nothing. (H.1). I started taking medication recently, I've never had stomach ache in my life. I never took anything, only since I was sixty (H.3).

The elderly men refer to past times, their childhood, youth, when they didn't use medications as they are understood today, but rather used medication practices which involved other therapeutic artifacts such as medicinal plants, used in the form of teas: When I was a child, we took remedies from the forest, my mother would collect leaves from the forest to make teas, I took them all my life and was healthy (H.2). In my childhood I never took any medication, there on the farm I used to take tea instead (H.17). As a sociocultural practice, the use of medicinal plants by the elderly men constitutes part of their therapeutic history and can persist over time, through intergenerational relationships, being substantiated in being used in 
conjunction with the medications dispensed by the primary healthcare center ${ }^{(11)}$.

The elderly men's representations related to the use of medications are anchored in the temporal perspective, that is, in the duality of youth and old age. Almost all of the interviewees' accounts evoke youth as an absence of illnesses - and, therefore, as non-use of medications. Old age, however, is perceived as a time of life in which health begins to disappear and the use of medications as routine practice, increasingly takes up these elderly men's daily life.

In the elderly men's perspective on ageing, being affected in old age by illnesses and pains, through the decline in physiological function, the reduction in resistance and the difficulty in recovering in specific conditions which were not there when they were young are emphasized by the elderly men ${ }^{(23)}$. Differently from women, the men represent old age as synonymous with illness, problems, limitations and pension, which can limit their active role after the age of sixty ${ }^{(24)}$.

In the elderly men's accounts, ageing appears as a synonym for illness. Thus, being old means being ill, and being ill implies taking medications: We used to live on the farm, but after I started going to the doctor, taking injections... (H.3); [...] At first, in the beginning, I never got ill, I started getting ill once I got old (H.5); [...] I really started taking medication after getting old, only recently have I taken lots of medications (H.6); [...] as a child I didn't take medicine, I didn't need it; it's five years since I had my stroke, I've been taking medications for five years. (H.8).

It is highlighted that the elderly man perceives his experience in the face of ageing in the dimensions of his own experience and his representations, youth being held as the ideal for the practice of everyday activities. This exercise, mediated by the representations which permeate the human-being-medication binomial, can frighten the man, who at this point of his life faces imposition of limits and conditions for daily tasks and the maintenance of life.

\section{The use of medication by the elderly man and perspectives of masculinity}

It is important to consider the presence of the woman in the use of medications by the elderly men. At some points in the interviews, the interviewees address their wife or the daughter to remember the medications which they use, their quantity, or to control their use: Dear! Wife! He wants to see the medicines I'm taking, get it all, bring it all over (H.3). There are four medicines a day, blood pressure, for diabetes I take insulin
(H.11). Sometimes I call the girl (daughter) over to control my medicines (H.13).

Social and cultural patterns are inserted into the elderly people's life contexts, and can influence the way of being male or female in old age. The man's role is anchored in the function of provider, of the individual who permeates the public spaces, who works, and who keeps order in the home. The woman is more directly involved with the family, with concern with the other relatives, as well as predominating in the private space, exercising a caring role with children, parents and spouse. In ageing, the man finds himself needing to re-make his perspective of gender, which reduces the hierarchical difference of the roles and establishes a cooperative relationship of mutual aid between man and wife(24).

In relation to the representations regarding the medications, and how these articulate with the perspectives of masculinity, the discourses are shown to be scattered and heterogeneous. One hand, the elderly man is considered to be one who does not care for himself, as can be verified in the following accounts: [...] men themselves, from 45 years old onwards, they have to care for themselves better, do some tests, and men don't want to do things like that, but that's normal (H.9); [...] in those days it was more about taking care of yourself than nowadays, because today I should be taking care of myself and I don't care for myself well (H.2). At other times, however, the use of medications, instead of supporting conceptions of frailty, historically related to the female gender, seem to evoke strategies for coping with the prescription of medications: [...] man, you're really strong, how can an ill person take this much medicine, and I tell them: I can bear it, and I've borne it up 'til now (H.4).

The male identity process involves important issues such as biological determinism and the meanings perceived in the body and, as a result, it seems convenient not to believe in the social and cultural construction of gender, but instead in the biological naturalness which is innate to man(25). The use of medications by elderly men also has - in the gender characteristics - the basis for such behavior. Thus, it becomes relevant for this aspect to be considered by the health professional, including the nurse, in men's healthcare.

\section{Final Considerations}

This research's findings allow one to be familiar with medication practices among elderly men, perceiving that these can follow or not the prescription specified for them by the doctor, in addition to altering it in line with their conceptions and needs. In the midst of these practices, 
the elderly man reports the incorporation of the use of medications into his day-to-day as permeated with ambivalence. This phenomenon, however, is permeated by important issues such as the medicalization of the male body, the obligation of the use, non-acceptance, and the susceptibility linked with polypharmacy.

The choices made are permeated with representations constructed over the elderly people's lives, that is, constructed in their experiences in relation to the use of medications, in experiences in their life trajectories, linked to illness and to their insertion in the health system. Through representations of illness linked to the ageing process, the elderly man with polypharmacy perceives a certain dependence on the medications and relies sometimes on his wife so as to be able to comply with the prescribed dosage, without losing his protagonism considering of the treatment. In this search, one can verify issues of gender, constructed based in cultural aspects.

In this way, the present research contributes to broadening health professionals' view regarding elderly men's use of medications, bearing in mind that the medication practices and the strategies used are not constituted in isolation, but are loaded with representations and meanings which strengthen the role of these subjects in their treatment in the daily routine. Effective actions on the part of the health professionals must be developed, principally in relation to drug therapy, in regard to monitoring and continuous education regarding the rational use by elderly men.

\section{References}

1. Gomes R, Nascimento EF, Araújo FC. Por que os homens buscam menos os serviços de saúde do que as mulheres? As explicações de homens com baixa escolaridade e homens com ensino superior. Cad Saúde Pública. 2007;23(3):565-74.

2. Machin $R$, Couto MT, Silva GSN, Schraiber RG, Gomes R, Figueiredo WS, et al. Concepções de gênero, masculinidades e cuidados em saúde: estudo com profissionais de saúde da atenção primária. Cienc Saúde Coletiva. 2011;16(11):4503-12.

3. Smith JA, Braunack-Mayer AJ, Wittert GA, Warin MJ. I've been independent for so damn long!: Independence, masculinity and aging in a help seeking context. J Aging Stud. 2007;21(4):325-35.

4. Mcvittie C, Willock J. You can't fight windmills: how older men do health, ill health, and masculinities. Qual Health Res. 2006;16(6):788-801.
5. Givens JL, Datto CJ, Ruckdeschel K, Knott K, Zubritsky C, Oslin DW, et al. Older Patients' aversion to antidepressants: a qualitative study. J Gen Intern Med. 2006;21:146-51.

6. Milder TY, Williams KM, Ritchie JE, Lipworth WL, Day RO. Use of NSAIDS for osteoarthritis amongst older-aged primary care patients: engagement with information and perception of risk. Age Ageing. 2011;40:254-9.

7. Campbell R, Pound P, Morgan M, Daker-White G, Britten N, Pill R et al. Evaluating meta-ethnography: systematic analysis and synthesis of qualitative research. Health Technol Assessm. 2011;15 (43): 1-180.

8. Rozenfeld S, Fonseca MJM, Acúrcio FA. Drug utilization and polypharmacy among the elderly: a survey in Rio de Janeiro City, Brazil. Rev Panam Salud Publica. 2008;23(1):34-43.

9. Szymczak JE, Conrad P. Medicalizing the aging male body: andropause and baldness. In: Rosenfeld D, Faircloth CA. Medicalized Masculinities. Philadelphia: Temple University Press; 2006. p. 89-111.

10. Solimeo SL, Weber TJ, Gold DT. Older men's explanatory model for osteoporosis. Gerontologist. 2011;51(4):530-9.

11. Lima SCS, Arruda GO, Renovato RD, Alvarenga MRM. Representations and uses of medicinal plants in elderly men. Rev. Latino-Am. Enfermagem. jul-ago 2012;20(4):778-86.

12. Conrad P. The meaning of medications: another look at compliance. Social Sci Med. 1985 20(1):29-37.

13. Hall S. The Work of Representation. In: Hall $S$, organizator. Representation: cultural representations and signifying practices. London: Sage; 1997.

14. Wyles $\mathrm{H}$, Rehman $\mathrm{HU}$. Inappropriate polypharmacy in the elderly. Eur J Intern Med. 2005;16(5):311-3.

15. Jovchelovitch S, Bauer MW. Entrevista narrativa. In: Bauer MW, Gaskell G. Pesquisa qualitativa com texto, imagem e som: um manual prático. 7. ed. Petrópolis Vozes; 2008. p. 90-113.

16. Foucault M. A Arqueologia do saber. 7th ed. Rio de Janeiro: Forense Universitária; 2005. 236 p.

17. Certeau M. A invenção do cotidiano: 1 . Artes de fazer. 14th.ed. Petrópolis: Vozes; 2008. 351 p.

18. Dal-Pizzol TS, Pons ES, Hugo FN, Bozzetti MC, Sousa MLR, Hilgert JB. Uso de medicamentos entre idosos residentes em áreas urbanas e rurais de município no Sul do Brasil: um estudo de base populacional. Cad Saúde Pública. 2012; 28(1):104-14. 
19. Schraiber LB, Figueiredo WS, Gomes R, Couto MT, Pinheiro TF, Machin $R$, et al. Necessidades de saúde e masculinidades: atenção primária no cuidado aos homens. Cad Saúde Pública. 2010;26(5):961-70.

20. Renovato RD, Bagnato MHS. Idosos hipertensos na atenção básica em saúde: discursos e identidades. Rev Bras Geriatr Gerontol. 2012;15(3):423-31.

21. Cunha KOA, Renovato RD, Descovi MS, Dal Vesco JR, Silva CA, Missio L, et al. Representações sobre o uso racional de medicamentos em equipes da Estratégia Saúde da Família. Rev Esc Enferm USP. 2012;46(6):1431-7.

22. Milder TY, Lipworth WL, Williams KM, Ritchie JE, Day RO. It looks after me: how older patients make decisions about analgesics for osteoarthritis. Arthritis Care Res. 2011;63(9):1280-6.

23. Gonzalez LMB, Seidl EMF. O envelhecimento na perspectiva de homens idosos. Paideia. (Ribeirão Preto). 2011;21(50):345-52.

24. Fernandes MGM. Papéis sociais de gênero na velhice: o olhar de si e no outro. Rev Bras Enferm. 2009;62(5):705-10.

25. Figueiredo WS, Schraiber LB. Concepções de gênero de homens usuários e profissionais de saúde de serviços de atenção primária e os possíveis impactos na saúde da população masculina, São Paulo, Brasil. Cienc Saúde Coletiva. 2011;16(1):935-44. 